\title{
ВЛИЯНИЕ ВЕЩЕСТВА НА ОСНОВЕ ФИБРОИНА ШЕЛКА НА ПОКАЗАТЕЛИ ЛИПИДНОГО ОБМЕНА У КРЫС С ЭКСПЕРИМЕНТАЛЬНОЙ ГИПЕРХОЛЕСТЕРИНЕМИЕЙ
}

\author{
${ }^{1}$ Нишантаев М. К., к. б. н. \\ ${ }^{1}$ Арифджанов С. 3., к. тех. н., дои. \\ ${ }^{1}$ Айходжаев Б. К., к. х. н., дои. \\ ${ }^{2}$ Юлдашев Н. М., д. б. н., проф.
}

Узбекистан, Ташкентский педиатрический медицинский институт;

${ }^{1}$ доиент кафедры медицинской и биологической химии,

медииинской биологии, общей генетики;

$2_{3}$ зведуюший кафедрой медицинской и биологической химии,

медииинской биологии, общей генетики

DOI: https://doi.org/ 10.31435/rsglobal_ws/31102018/6177

\section{ARTICLE INFO}

Received: 06 August 2018

Accepted: 14 October 2018

Published: 31 October 2018

\section{KEYWORDS}

Enterosorption;

fibroin silk;

experimental hypercholesterolemia;

cholesterol;

bile acids;

bilirubin.

\begin{abstract}
The article presents the results of a study on the effectiveness of a substance based on silk fibroin, obtained at the Institute of Chemistry and Polymer Physics of the Academy of Sciences of the Republic of Uzbekistan, in eliminating disorders of lipid metabolism in the body. In experiments in rats with experimental hypercholesterolemia, the substance was found to have a cholesterol-lowering property, which is manifested by a decrease in cholesterol level both in blood and in tissues. Studies on the mechanism of the hypocholesterolemic effect of the studied substance have shown its effects on the enterohepatic pathway of bile acids, which makes it possible to classify this substance as a group of bile acid sequestrants.
\end{abstract}

Citation: Нишантаев М. К., Арифджанов С. 3., Айходжаев Б. К., Юлдашев Н. М. (2018) Vliyanie Veschestva na Osnove Fibroina Shelka na Pokazateli Lipidnogo Obmena u Kris s Eksperimentalnoi Giperholesterinemiei. World Science. 10(38), Vol.1. doi: 10.31435/rsglobal_ws/31102018/6177

Copyright: (C) 2018 Нишантаев М. К., Арифджанов С. З., Айходжаев Б. К., Юлдашев Н. М. Тhis is an open-access article distributed under the terms of the Creative Commons Attribution License (CC BY). The use, distribution or reproduction in other forums is permitted, provided the original author(s) or licensor are credited and that the original publication in this journal is cited, in accordance with accepted academic practice. No use, distribution or reproduction is permitted which does not comply with these terms.

Введение. Энтеросорбция - один из способов лечения заболеваний, обладает целым рядом преимуществ в сравнении с применением лекарственных средств. Это обусловлено тем, что большинство энтеросорбенты практически не всасываются через желудочно-кишечный тракт в связи с чем, исключается вмешивание их в метаболические процессы, протекающие в организме. В результате изысканий учёных Института химии и физики полимеров АН Республики Узбекистан, было получено вещество белковой природы из отходов шёлкового производства. Данный продукт представляет собой кристаллический порошок кремового цвета. Он без запаха, слабокислый на вкус, гигроскопичен, нерастворим в воде, растворим в 63\% $\mathrm{NaCNS}$ и 44\% $\mathrm{CaCl}_{2}$. Предварительное исследование, проведённое нами, показало, что данное вещество не переваривается в желудочном соке, о чём свидетельствовало не изменения содержания аминного азота в желудочном соке при его инкубации в желудочном соке. Нами проведены исследования по изучению эффективности данного вещества, условно названного БС-1 (Биологический сорбент - 1) в устранении нарушений липидного обмена в эксперименте.

Цель исследования. Оценка эффективности вещества БС-1 в устранении нарушений липидного обмена при экспериментальной гиперхолестеринемии (ГХС) моделированной у крыс. 
Материал и методы исследования. Опыты проведены на 55 белых крысах-самцах массой тела 200-250 г. Животные содержались в стандартных условиях вивария при естественном освещении и свободном доступе к воде и пище. Протокол экспериментов соответствовал этическим нормам, изложенным в «Правилах проведения работ с использованием экспериментальных животных», а также в Директиве 2010/63/EU Европейского парламента и Совета Европейского Союза по охране животных, используемых в научных целях.

Экспериментальную ГХС у 15 крыс (контрольная группа) вызывали путём ежедневного перорального введения 2 мл смеси спиртового и масляного растворов витамина Д2 из расчёта 80000 ЕД на 100 г массы и ХС в дозе 200 мг/кг, дополнительно к обычному лабораторному рациону, в течение 6 дней [6]. В опытной группе животным (15 крыс) перорально вводили вещество БС-1 одновременно с ХС и витамином Д2 в дозе 0,5 г/кг. Параллельно изучали липидные показатели у 10-и интактных животных. Животных, находящихся под эфирным наркозом, декапитировали на 7-е сутки опыта.

В сыворотке крови содержание холестерина, общих липидов, триглицеридов определяли с помощью тест-наборов фирмы "Lachema" (Чехия). Содержание общих фосфолипидов в сыворотке крови определяли в экстракте общих липидов, выделенный смесью хлороформа и метанола. Экстракция общих липидов из печёночной ткани и аорты осуществляли 20-кратным объёмом смеси хлороформа и метанола в соотношении 2:1 по Фолчу [5] и далее гравиметрическим методом определяли их содержание. Содержание холестерина, триглицеридов в экстрактах печёночной ткани, а также холестерина в экстрактах аорты определяли с помощью тест-наборов фирмы "Lachema" (Чехия). Содержание фосфолипидов в экстрактах крови, печёночной ткани и аорты определяли по количеству фосфора методом Свенберга и Свеннерхолма (1963) после минерализации липидного экстракта в смеси серной и хлорной кислоты [8].

Для приближения опыта к условиям, наблюдающимся в кишечнике, были проведены исследования по изучению сорбционной способности БС-1 к основным компонентам желчи желчным кислотам, холестерину и билирубину. При этом была использована дуоденальная желчь человека, полученная при диагностическом зондировании. Для определения максимальной сорбции изучаемых веществ, к образцам БС-1 в 10,0 мг добавляли возрастающие объёмы $(0,5,1,0,1,5$ и 2,0 мл) дуоденальной желчи. Образцы инкубировали в течение 3 часов при $37^{\circ} \mathrm{C}$, постоянно перемешивая содержимое пробирок. По истечении времени инкубации БС-1 отделяли центрифугированием, и в супернатанте определяли концентрацию желчных кислот и холестерина по [7]. Содержание билирубина определяли по [9].

У 15 животных с экспериментальной ГХС изучали также влияние БС-1 на секрецию и состав желчи. Желчь для исследования собирали в течение 4 часов под этаминаловым наркозом (50 мг/кг внутрибрюшинно) канюлированием общего желчного протока; измеряли её объем и определяли содержание желчных кислот, холестерина и билирубина по вышеуказанным методам.

Статистическую обработку полученных результатов проводили с помощью стандартных методов вариационной статистики с применением t-критерия Стьюдента.

Результаты исследования. Проведённые исследования выявили ряд существенных изменений липидного обмена в сыворотке крови у крыс, при их кормлении экзогенным холестерином. У животных с ГХС содержание общих липидов было повышено на 228\% по сравнению с нормой. Концентрация холестерина также была повышена на 205\% по сравнению с интактным значением. При этом содержание общих фосфолипидов оставалось на уровне интактных животных. Интересным фактом является резкое снижение уровня триглицеридов. Оно составило всего 29,6\% интактного значения (табл. 1).

Таблица 1. Влияние вещества БС-1 на содержание липидов в сыворотке крови у крыс с гиперхолестеринемией (мг\%)

\begin{tabular}{|c|c|c|c|}
\hline \multirow{2}{*}{ Показатели } & \multicolumn{3}{|c|}{ Группы } \\
\hline & интактная & контрольная (ГХС) & опытная (ГХС + БС-1) \\
\hline Общие липиды & $234,78 \pm 20,35$ & $535,26 \pm 38,36^{\mathrm{a}}$ & $384,06 \pm 15,14^{\mathrm{a}, \sigma}$ \\
\hline Холестерин & $73,94 \pm 4,46$ & $151,93 \pm 5,14^{\mathrm{a}}$ & $108,15 \pm 3,28^{\mathrm{a}, \text { б }}$ \\
\hline Триглицериды & $70,81 \pm 2,18$ & $20,98 \pm 0,78^{\mathrm{a}}$ & $35,39 \pm 2,28^{\mathrm{a}, \sigma}$ \\
\hline Фосфолипиды & $122,00 \pm 9,79$ & $128,24 \pm 1,40^{\mathrm{a}}$ & $187,14 \pm 11,33^{\mathrm{a}, \sigma}$ \\
\hline
\end{tabular}

Примечание: здесь и в табл. 2, 3 и 5: а - P < 0,05 по сравнению с интактными показателями, б - P < 0,05 по сравнению с контрольными показателями.

При лечении животных с веществом БС-1 содержание общих липидов и холестерина статистически значимо снизилось на 28,3 и 28,8\% соответственно по сравнению с контрольными значениями, оставаясь при этом выше интактных значений на 163,5 и 46,3\% соответственно. 
Энтеросорбция в течение 6 дней способствовала повышению содержания общих фосфолипидов на 53,4 и 45,9\% по сравнению с интактным и контрольным значением соответственно. Наблюдали также повышения уровня триглицеридов у леченных животных на $68,7 \%$ по сравнению с контрольным значением, хотя по сравнению с нормой он оставался сниженным на 50,0\%.

Результаты исследования показали, что ГХС сопровождается повышением в ткани печени содержания общих липидов и холестерина на 167,5 и 405\% по сравнению с интактными значениями (табл. 2).

Таблица 2. Влияние вещества БС-1 на содержание липидов в печёночной ткани у крыс с гиперхолестеринемией (мг/г ткани)

\begin{tabular}{|c|c|c|c|}
\hline \multirow{2}{*}{ Показатели } & \multicolumn{3}{|c|}{ Группы } \\
\hline & интактная & контрольная (ГХС) & опытная (ГХС + БС-1) \\
\hline Общие липиды & $57,14 \pm 1,89$ & $95,71 \pm 0,84^{\mathrm{a}}$ & $68,04 \pm 4,03^{a, \sigma}$ \\
\hline Холестерин & $3,11 \pm 0,15$ & $12,60 \pm 0,33^{\mathrm{a}}$ & $5,99 \pm 0,80^{\mathrm{a}, \sigma}$ \\
\hline Триглицериды & $14,96 \pm 0,19$ & $15,41 \pm 0,21$ & $13,93 \pm 0,19^{6}$ \\
\hline Фосфолипиды & $3,16 \pm 0,03$ & $3,24 \pm 0,02$ & $2,85 \pm 0,10^{\sigma}$ \\
\hline
\end{tabular}

У животных, получавших вещество БС-1 содержание общих липидов в печёночной ткани статистически значимо снизилось на 29\% по сравнению с контрольным значением, превышая всего на 19\% интактные значения. Уровень холестерина в ткани печени у опытных животных (животные с лечением) также был снижен на 52,5\% по сравнению с контролем, хотя по сравнению с нормой он был выше на 92,6\%. Содержание триглицеридов и фосфолипидов после энтеросорбции стало ниже даже по сравнению с исходным значением на 7 и 10\% соответственно.

Полученные результаты показали, что при ГХС уровень холестерина в аорте повысился на 96,5\% от интактного значения. В содержании общих фосфолипидов также наблюдали повышение на 55,5\% по сравнению с интактным значением (табл. 3).

Таблица 3. Влияние вещества БС-1 на содержание липидов в аорте у крыс с гиперхолестеринемией

\begin{tabular}{|l|c|c|}
\hline \multirow{2}{*}{\multicolumn{1}{|c|}{ Группы }} & \multicolumn{2}{|c|}{ Липиды, в мг/г ткани } \\
\cline { 2 - 3 } & холестерин & фосфолипиды \\
\hline интактная & $3,73 \pm 0,29$ & $5,39 \pm 0,29$ \\
\hline контрольная $($ ГХС) & $7,33 \pm 0,1^{\text {a }}$ & $8,38 \pm 0,45^{\text {a }}$ \\
\hline опытная (ГХС + БС-1) & $5,48 \pm 0,34^{\text {a, }}$ б & $7,14 \pm 0,42^{\text {a, б }}$ \\
\hline
\end{tabular}

У животных, получавших вещество БС-1 содержание холестерина в аорте было снижено на 25,2\% по сравнению с контрольным значением. Уровень общих фосфолипидов в аорте тоже снизился на 14,8\% по сравнению с нелечеными животными, оставаясь при этом выше интактных значений на $32,5 \%$.

Для понимания механизма гипохолестеринемического действия вещества БС-1 изучали его способность сорбировать компонентов желчи - желчных кислот, холестерина и билирубина.

Результаты исследования показали, что при инкубации вещества БС-1 с дуоденальной желчью наблюдается значительное снижение в ней содержания холестерина и желчных кислот. Так, содержание холестерина на 30, 60, 120 и 180 минут инкубации оказалось статистически достоверно ниже от исходной концентрации соответственно на 19,4, 16,4, 49,0 и 58,5\% (табл. 4).

Таблица 4. Сорбция холестерина и желчных кислот из дуоденальной желчи $(0,5$ мл) веществом БС-1 (10 мг) в динамике времени

\begin{tabular}{|c|c|c|c|}
\hline & & Холестерин & Желчные кислоты \\
\hline \multicolumn{2}{|c|}{ исходная концентрация в желчи, мг \% } & $4,94 \pm 0,34$ & $131,32 \pm 6,58$ \\
\hline \multirow{4}{*}{$\begin{array}{c}\text { концентрации } \\
\text { (мг \%) при инкубации желчи } \\
\text { веществом БС-1 в динамике } \\
\text { (минуты) }\end{array}$} & 30 & $3,98 \pm 0,28 *$ & $92,27 \pm 1,45^{*}$ \\
\hline & 60 & $4,13 \pm 0,09 *$ & $102,90 \pm 2,99 *$ \\
\hline & 120 & $2,52 \pm 0,05^{*}$ & $88,00 \pm 1,21 *$ \\
\hline & 180 & $2,05 \pm 0,07 *$ & $80,56 \pm 1,87 *$ \\
\hline
\end{tabular}

Примечание: * - достоверность по сравнению с исходными данными. 
Содержание желчных кислот на 30, 60, 120 и 180 минут инкубации оказалось также статистически достоверно ниже от исходной концентрации соответственно на 29,7, 21,6, 33,0 и 38,7\%.

Далее нами изучалось влияние вещества БС-1 на секрецию желчи и на содержание её компонентов в in vivo условиях. Результаты показали, что при добавлении вещества БС-1 к гиперхолестеринемическому рациону наблюдается снижение секреции желчи на 25,6\% и уменьшение содержания билирубина на 17,7\% по сравнению с контрольной группой (табл. 5).

Таблица 5. Влияние вещества БС-1 на секрецию и состав желчи у крыс с гиперхолестеринемией

\begin{tabular}{|l|c|c|c|}
\hline \multirow{2}{*}{\multicolumn{1}{|c|}{ Показатели }} & \multicolumn{3}{|c|}{ Группы } \\
\cline { 2 - 4 } & интактная & контрольная (ГХС) & опытная (ГХС+БС-1) \\
\hline $\begin{array}{l}\text { Секреция желчи, } \\
\text { мл/100 Г } 4 \text { ч ч. }\end{array}$ & $1,20 \pm 0,006$ & $1,17 \pm 0,008$ & $0,87 \pm 0,005^{\text {a, }}$ \\
\hline Желчные кислоты, мг/мл & $4,50 \pm 0,029$ & $4,80 \pm 0,085^{\text {a }}$ & $4,15 \pm 0,050^{\text {a, }}$ \\
\hline Холестерин, мг/мл & $0,164 \pm 0,008$ & $0,124 \pm 0,007^{\mathrm{a}}$ & $0,139 \pm 0,009^{\mathrm{a}, ~}$ \\
\hline Билирубин, мкг/мл & $86,8 \pm 2,8$ & $88,6 \pm 3,9$ & $72,9 \pm 2,5^{\mathrm{a}, ~}$ \\
\hline
\end{tabular}

Также на фоне повышения уровня холестерина в желчи на $12,1 \%$, снижалось количество желчных кислот в ней на 13,5\% по сравнению с нелеченой группой. Следовательно, применение гиперхолестеринемической диеты с включением вещества БС-1 оказывало определённое влияние на секрецию и состав желчи у крыс, что подчёркивает тесную взаимосвязь метаболизма холестерина и желчных кислот.

Таким образом, в опытах на крысах, получавших ГХС диету, добавление вещества БС-1 привело к снижению содержания общих липидов, холестерина, триглицеридов в крови, печёночной ткани и аорты, что свидетельствует об эффективном гиполипидемическом и гипохолестеринемическом действии данного вещества.

Обсуждение результатов исследования. Эпидемиологические исследования, а также экспериментальные и клинические наблюдения позволили выделить факторы риска развития атеросклероза и его осложнений, главным из которых является гиперлипидемия [11]. Было показано, что длительное снижение уровня общего холестерина в крови больных с гиперлипидемией на 9-10\% сопровождается снижением риска развития ишемической болезни сердца на 25\% [12]. В то же время у больных с гиперлипидемией, перенёсших инфаркт миокарда, такое же по степени снижение уровня общего холестерина уменьшает риск повторного инфаркта на 6\% [14]. Эксперты ВО3 отмечают, что существенным для раннего укрепления здоровья является научно обоснованное рациональное питание [16]. В связи с этим представляют интерес данные о структуре питания населения экономически развитых стран. В количественном отношении в развитых странах увеличилось потребление продуктов животного происхождения и легкоусвояемых углеводов, резко снизилось потребление растительной пищи, в частности, богатой волокнами [10]. Недостаточное потребление последних связывают с нарастанием "болезней цивилизации" $[1,2,15]$. В развивающихся странах используется преимущественно растительная пища, богатая пищевыми волокнами, и у населения даже в старости редко регистрируются ишемическая болезнь сердца и другие заболевания, относимые к "болезням цивилизации" [13]. Единой классификации пищевых волокон нет, поэтому, многие авторы обозначают их как неперевариваемые в тонкой кишке некрахмальные полисахариды (целлюлоза, гемицеллюлоза, пептин, гумми, слизи) и не углеводное соединение лигнин.

Связывая и тем самым препятствуя всасыванию в кишечнике ряда соединений, например, желчных кислот, являющихся продуктом деградации холестерина [15], а также потенциально токсических веществ, поступающих в кишечник с большим количеством пищеварительных соков, пищевые волокна оказывают энтеросорбционную детоксикацию организма и способствуют снижению гиперлипидемии [4].

Изученное нами вещество получено из отходов шёлкового производства и является веществом белковой природы. По сути это белок фиброин, относящийся к классу фибриллярных белков [3]. Он показал довольно хороший гипохолестеринемический эффект. Так, при пероральном введении БС-1 крысам с экспериментальной гиперхолестеринемией наблюдали снижение содержания холестерина и общих липидов в крови, на фоне повышения уровня общих фосфолипидов. При лечении экспериментальной ГХС наблюдали также значительное снижение уровня холестерина как в печёночной ткани, так и в аорте.

Естественно возникает вопрос о механизме гипохолестеринемического действия изученного вещества. Для его понимания был проведён эксперимент, где изучалось сорбционная 
ёмкость вещества БС-1 по отношению к желчным кислотам и холестерину. Результаты in vitro опытов показали, что данное вещество сорбирует значительное количество как холестерина (до $60 \%$ ), так и желчных кислот (до 40\%) при инкубации его с дуоденальной желчью. На основании этих результатов, нами была изучена секреция желчи и содержание компонентов желчи у крыс с экспериментальным ГХС при введении вещества БС-1. Результаты показали, что при 6 дневное введение вещества БС-1 приводит к снижению секреции желчи, но при этом наблюдается также снижение в ней содержания желчных кислот и билирубина.

Результаты исследования свидетельствуют о влиянии вещества БС-1 на энтерогепатический путь желчных кислот, наподобие секвестранта желчных кислот холестирамина. При введении вещества БС-1 желчные кислоты связываются с ним и выводятся из организма, что резко уменьшает их количество, попадающих в печень через энтерогепатический путь. Снижение содержания желчных кислот стимулирует их синтез из холестерина, за счёт чего снижается содержание последнего в печени. Усиление распада холестерина для образования желчных кислот с одной стороны, блокирование всасывания пищевого жира и холестерина в кишечнике за счёт дефицита свободных желчных кислот, с другой стороны, приводит к снижению содержания холестерина во всём организме.

Таким образом, результаты проведённых исследований показали наличие гипохолестеринемического действия у вещества БС-1, что позволит рекомендовать его для снижения уровня холестерина при гиперхолестеринемии и атеросклерозе.

\section{ЛИТЕРАТУРА}

1. Бонацская Л. В., Зиневич А. К. Энтеросорбция как метод профилактики и лечения некоторых осложнений консервативной терапии опухолевой болезни // Сорбционные методы детоксикации и иммунокоррекции в медицине. Тез. докл. - Харьков, 1982. - С. 4.

2. Броновец И. Н. Пищевые волокна - важная составляющая сбалансированного здорового питания // Медицинские новости. - 2015. - № 10 (253). URL: https://cyberleninka.ru/ article/n/pischevye-voloknavazhnaya-sostavlyayuschaya-sbalansirovannogo-zdorovogo-pitaniya (дата обращения: 21.10.2018).

3. Зенгбуш П. Молекулярная и клеточная биология. М.: «Мир», 1982. 1 том. - 366 с.

4. Климов А. Н., Рыженков В. Е. Гиполипидемические препараты / Клиническая фармакология. - М.: Медицина, 1978. - С. 380-392.

5. Методы биохимических исследований (липидный и энергетический обмен) /Под ред. М. И. Прохоровой. - Л.: Ленингр. ун-та, 1982. - 272 с.

6. Окуневич И. В., Рыженков В. Е. Антиатеросклеротическое действие милдроната в эксперименте. // Пат. физиол. и эксп. тер. - 2002. - № 2. - С. 24-27.

7. Определение содержание желчных кислот и холестерина в желчи / В. П. Мирошниченко, Л. Л. Громашевская, М. Г. Касаткина, Г. А. Козачек // Лаб. дело. - 1978. - № 3. - С. 149-153.

8. Определение содержания фосфолипидов // Современные методы исследования липопротеидов высокой плотности (методические рекомендации). - М, 1983. - С. 21-23.

9. Скакун Н. П. Определение содержания билирубина в желчи // Проблемы эндокринологии и гормонотерапии. - 1956. - № 6. - С. 53-55.

10. Современные направления использования пищевых волокон в качестве функциональных ингредиентов / М. П. Могильный, Т. В. Шлёнская, М. К. Галюкова, Т. Ш. Шалтумаев, А. Ю. Баласанян // Новые технологии. - 2013. - №1. - С. 27-31.

11. Факторы риска атеросклероза и клинико-морфологические сопоставления при системных васкулитах / Л. А. Стрижаков, Моисеев С. В., Коган Е. А., Диттерле В. Е., Семенкова Е. Н., Кузнецова Е. И. // Научно-практическая ревматология. - 2012. - № 4 (53). - С. 18-23.

12. Coronary Drug Project Research Group // J. Amer. Med. Ass. - 1975. - v. 231. - P. 360.

13. Gibney M. J. Nutrition, diet and health. Cambridge Univ. Press London, New York, 1986. - 168 p.

14. Gotto A. M. Status Report: plasma lipids, lipoproteins and coronary artery disease // Atheroscl. Rev. 1979. - v. 9. - P. 17-28.

15. Heinemann L., Barth W., Thiel C. Internationale lusam menhange von ernahrung und mortalitatstrends // J. Clin. Med. - 1986. - v. 41, № 25. - P. 2075-2078.

16. Wagner G. Whither goest nutrition? // Nutr. and Health. - 1986. - v. 4, № 3. - P. 135-140. 